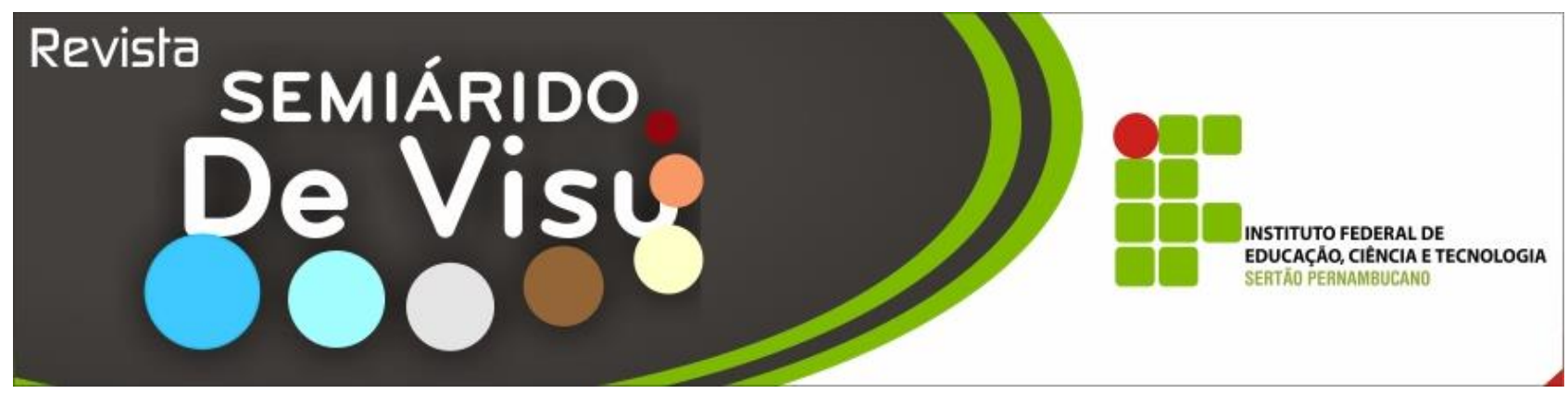

\title{
Propagação vegetativa de cacaueiros pelo processo de estaquia, sob diferentes concentrações de ácido indolbutírico
}

\author{
Marcelo de Campos Pereira1 ${ }^{1}$ Laise de Sousa Santos², Silvana Souza Martins³, Meridiana Araújo \\ Lima $^{4}$, Valtemir Gonçalves Ribeiro ${ }^{5}$
}

\begin{abstract}
${ }^{1}$ Instituto Federal do Sertão Pernambucano - campus Salgueiro. BR 232, Km 508, sentido Recife, Zona Rural - Salgueiro Pernambuco - Brasil. CEP: 56000-000 / Telefone: (87) 3421-0050 / E-mail: marcelo.pereira @ ifsertao-pe.edu.br;

2,3,4,5 Universidade do Estado da Bahia - campus III. Av Edgard Chastinet, s/n - Juazeiro - Bahia - Brasil. CEP: 48905-680/

Telefone: (74) 3611-5617 / E-mail: laysousa1@hotmail.com, martins.silvana@bol.com.br, meridiana.araujo@gmail.com, valtemir.ribeiro@gmail.com;
\end{abstract}

RESUMO: Dois experimentos foram conduzidos em viveiro de mudas e casa de vegetação em Juazeiro-BA. Foram utilizadas estacas semilenhosas dos clones CCN-51, PS-1319 e PH-16, com 3 a 4 gemas. Posteriormente, as estacas de CCN-51 e PS-1319 foram submetidas a concentrações de 0, 2000, 4000 e 6000 mg.. $\mathrm{L}^{-1}$ de AIB realizando-se imersão de suas bases pelo tempo de 10 segundos e as estacas de PH-16 foram tratadas com 0, 300, 600 e $900 \mathrm{mg}^{-L^{-1}} \mathrm{de}$ AIB com imersão de suas bases por 24 h. Logo após, as estacas foram colocadas em sacos de poliestireno, contendo substrato à base de areia, esterco e terra vegetal na proporção de 3:2:1, respectivamente. Os experimentos foram avaliados aos 60 dias da instalação. As estacas utilizadas no experimento I apresentaram baixo índice de sobrevivência, brotação e formação de calos. De forma similar o experimento II apresentou baixo índice de sobrevivência e formação de calos, porém não ocorreram brotações, sendo que nos dois experimentos não houve formação de raízes.

Palavras-chave: Theobroma cacao L, vegetal, auxina.

\section{Vegetative propagation of cocoa trees by cutting process under different concentrations of IBA}

\begin{abstract}
Two experiments were conducted in nursery and greenhouse, both located in Juazeiro-BA. We used softwood cuttings of clones CCN-51, PS-1319 and PH-16, with 3 to 4 buds. The cuttings of CCN-51 and PS-1319 were subjected to concentrations of 0, 2000, 4000 and $6000 \mathrm{mg} . \mathrm{L}-1$ IBA carrying out of their bases by the immersion time of 10 seconds and the stakes of PH-16 were treated with 0, 300, 600 and $900 \mathrm{mg} . \mathrm{L}-1$ IBA immersion of their bases for 24 h. Soon after, the cuttings were placed in polystyrene bags containing sand-based substrate, manure and topsoil in the ratio of 3: 2: 1, respectively. The experiments were assessed at 60 days of installation. The cuttings used in experiment one showed a low survival rate, shoot and callus formation. Similarly the second experiments showed a low rate of survival and callus formation, but there were no shoots, but in the two experiments did not form roots.
\end{abstract}

keywords: Theobroma cacao L, vegetable, auxin. 


\section{Introdução}

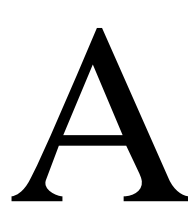

cacauicultura representa uma atividade de grande importância econômica, sendo o cacau uma commodity agrícola, com muitos países envolvidos na sua produção, comercialização e consumo (PEREIRA et al., 2009). No Brasil, a maior área de produção de cacau encontra-se na Bahia, com aproximadamente 29 mil propriedades, em uma área de 559 mil ha (SANTOS JUNIOR et al., 2008).

O cultivo do cacaueiro (Theobroma cacao L.) no Semiárido baiano, onde as condições edafoclimáticas diferem das encontradas no sul do estado (PEREIRA et al., 2009), região onde se concentra a maior produção nacional, pode ampliar a fronteira agrícola dessa cultura e elevar o Brasil a uma posição mais destacada no cenário mundial, como ocorreu nos anos 80, quando o País chegou a ser o segundo maior produtor, atrás apenas da Costa do Marfim.

A queda da produção nacional de cacau ocorreu, dentre outros fatores, em virtude da disseminação da vassoura-de-bruxa (Moniliophtora perniciosa Stahel Aime \& Phillips-Mora) na região Sul da Bahia, doença esta que dizimou grande parte das áreas de cultivo. Como medida para o controle dessa enfermidade a partir de 1989, começou a substituição de cacaueiros suscetíveis, de origem seminal, por plantas tolerantes, propagadas vegetativamente pelos métodos de enxertia e estaquia (FARIA; SACRAMENTO, 2003).

$\mathrm{Na}$ maioria das plantas frutíferas, a propagação é realizada pelo método de estaquia, que, além de proporcionar muda de qualidade, fixa características agronômicas desejáveis de forma eficiente (BASTOS et al., 2005). A estaquia, aliada ao uso de reguladores vegetais é atualmente o método mais indicado para propagar cacaueiros tolerantes a vassoura de bruxa, em virtude da produção de clones idênticos e de não apresentar o problema da incompatibilidade, que pode ocorrer na enxertia. Tratamentos de estacas com reguladores de crescimento estimulam à iniciação radicular, proporciona redução no tempo de formação das mudas, com consequente diminuição da permanência das estacas no local de enraizamento e dá origem a pomares mais homogêneos, representando uma evolução no seu cultivo (BASTOS et al., 2005). $\mathrm{O}$ ácido indolbutírico (AIB) é a auxina mais comumente utilizada na indução do enraizamento adventício (VILLA et al., 2003) das estacas das mais diversas culturas. A aplicação exógena de reguladores de crescimento, principalmente as auxinas, tais como o AIB, auxina sintética mais utilizada (MACHADO et al., 2005), por possuir comprovada atividade auxínica (LOPES et al., 2003) e estimular a síntese de etileno, que favorece a emissão de raízes (NORBERTO et al., 2001) é uma das formas mais comuns de fazer o balanceamento hormonal para o enraizamento, elevando o teor de auxina nos tecidos (PASQUAL et al., 2001).

Mediante o exposto, o presente trabalho teve por objetivo avaliar a formação de mudas através de estacas semilenhosas de clones de cacaueiros, tratadas com diferentes concentrações de AIB em dois ambientes.

\section{Material e métodos}

O experimento foi conduzido em viveiro de mudas e casa de vegetação, ambos localizados no município de Juazeiro, BA. Os clones utilizados foram CCN-51, PS-1319 e $\mathrm{PH}-16$, provenientes do campo experimental localizado na Universidade do Estado da Bahia (UNEB), campus III. Foram utilizadas estacas semilenhosas oriundas de ramos plagiotrópicos com 3 a 4 gemas, das quais retiraram-se todas as folhas. Posteriormente, as estacas dos clones CCN-51 e PS-1319 foram submetidas a concentrações de $0,2.000,4.000$ e $6.000 \mathrm{mg} . \mathrm{L}^{-}$ ${ }^{1}$ de AIB, realizando-se imersão de suas bases $(2 \mathrm{~cm})$ pelo tempo de 10 segundos e as estacas do clone PH-16 foram tratadas com AIB nas concentrações de 0, 300, 600 e $900 \mathrm{mg} . \mathrm{L}^{-1} \mathrm{em}$ imersão de suas bases $(2 \mathrm{~cm})$ por $24 \mathrm{~h}$.

Após a aplicação dos tratamentos, as estacas foram colocadas em sacos de poliestireno com dimensões de $10 \times 15 \mathrm{~cm}$, 
contendo substrato à base de areia, esterco e terra vegetal na proporção de 3:2:1, respectivamente. A profundidade do estaqueamento foi de $2 / 3$ do tamanho da estaca. $O$ viveiro (sem nebulização) e a casa de vegetação (com nebulização intermitente) possuíam malhas que permitiam a passagem de $50 \%$ de luminosidade. $\mathrm{O}$ experimento conduzido no viveiro (I) foi umedecido diariamente via regas manuais e pelo sistema de irrigação por aspersão, sendo que os ápices das estacas foram envolvidos com sacos plásticos transparentes, objetivando-se minimizar a desidratação. $\mathrm{O}$ experimento montado em casa de vegetação (II) possuía irrigação por nebulização intermitente a cada 10 minutos, com duração de 60 segundos.

Durante o período de condução do experimento I, entre outubro e dezembro de 2010, a temperatura média foi de $27,3{ }^{\circ} \mathrm{C}$ e a umidade relativa do ar variou de 63 a $76 \%$. No experimento II, durante período experimental, de janeiro a fevereiro de 2011, a temperatura média foi de $26,5{ }^{\circ} \mathrm{C}$, e a umidade relativa do ar oscilou entre 80 e $90 \%$.

Os experimentos foram avaliados aos 60 dias da instalação, em relação às seguintes características: índice de sobrevivência, número de gemas brotadas e formação de calos e raízes.

O delineamento experimental utilizado no experimento I foi o de blocos casualizados, em esquema fatorial 4 (concentrações de AIB) x 2 (clones), CCN-51 e PS-1139, com quatro repetições, contendo dez estacas por unidade experimental. Para o experimento II foi utilizado o esquema de blocos casualizados, quatro concentrações de AIB, um clone (PH16), com quatro repetições, contendo dez estacas por unidade experimental.

\section{Resultados e discussão}

De acordo como resumo da a análise de variância (Quadro 1) observa-se que das características analisadas, houve diferença estatística significativa a $5 \%$ de probabilidade apenas para a característica formação de calos, em relação fator clones no experimento I. Não houve efeito estatístico significativo da utilização do AIB para a porcentagem de sobrevivência, de brotação e formação de calos nas estacas.

No experimento I, os resultados da avaliação, aos 60 dias após o estaqueamento demonstraram que o índice de sobrevivência dos clones CCN-51 e PS-1319 não foi influenciado pelas concentrações de AIB, não sendo verificada diferença estatística entre concentrações aplicadas e a testemunha. Resultado similar foi encontrado por Faria e Sacramento (2003) trabalhando com o clone CEPEC-42, onde não se verificou influencia da aplicação de AIB (0 e $6.000 \mathrm{mg} \cdot \mathrm{kg}^{-1}$ ) sobre a sobrevivência de estacas.

Os clones CCN-51 e PS-1319 não demonstraram diferença em relação ao número de estacas vivas e as concentrações de AIB, apresentando uma baixa taxa de sobrevivência das estacas (Quadro 2). Santos Júnior et al. (2008) verificaram que concentrações crescentes de AIB não reduziram o número de estacas mortas do clone PS-1319. Sodré (2007), trabalhando com miniestacas de Theobroma cacao, em câmara de nebulização com controle do ambiente (água, luz e temperatura), tratadas com 6.000 mg. $\mathrm{kg}^{-1}$ de AIB, verificou que os valores encontrados para a porcentagem de sobrevivência de estacas não diferiram estatisticamente entre os tratamentos com diferentes substratos e clones.

As plantas (estacas) do experimento I apresentaram brotação das gemas e formação de calos sem formação de raízes. Não houve diferença estatística entre as concentrações de AIB aplicadas e as brotações das estacas. Os clones apresentaram índice de brotação inferior a $1,0 \%$, não diferindo estatisticamente entre si. Já em relação à formação de calos, os clones CCN-51 e PS-1319 apresentaram respostas diferentes, ou seja, índices de 1,250\% e de $0,625 \%$, respectivamente (Quadro 3). Dados estes contrastantes aos observados por Faria e Sacramento (2003), que independentemente da aplicação de AIB, estacas dos clones CEPEC42, TSH-516 e TSH-1188 apresentaram índices de enraizamento superiores a $87 \%$, e aos de Leite e Martins (2007) que obtiveram um valor médio de sobrevivência de 75,5 e 50,7\%, no verão e inverno, respectivamente, para os clones CEPEC-2008, CCN-51 e TSH-1188, 
sendo que nestes trabalhos foram utilizadas estacas com folhas recortadas à metade, em ambiente com sistema de nebulização intermitente.

No experimento II verificou-se, de forma similar ao ocorrido no experimento I, que índices de sobrevivência e de formação de calos das estacas do clone $\mathrm{PH}-16$ não foram influenciadas pelas concentrações de AIB aplicadas, não havendo diferença estatística entre os tratamentos (Quadro 4), porém, não houve brotação de gemas, apesar de estarem em ambiente com nebulização intermitente, que proporcionou uma umidade relativa do ar em torno de 80 a $90 \%$, para minimizar a desidratação das estacas.

A brotação das gemas das estacas, no experimento I antes do enraizamento pode ter levado-as à morte, pois estas estruturas funcionam como dreno metabólico, que consomem as reservas de carboidratos e de compostos nitrogenados das estacas (LIMA et al., 2006). Além disso, tratando-se de enraizamento de estacas de cacaueiro, condições de viveiro podem influir no crescimento e afetar a capacidade de enraizamento, segundo PYKE (1933). Esse mesmo autor verificou nesse contexto que estacas semilenhosas apresentam maiores enraizamentos e que a presença de folhas nas estacas é necessária para o sucesso da formação de raízes. Porém Vale et al. (2008) trabalhando com estacas de goiabeira verificaram que a simples presença das folhas nas estacas não teve qualquer influência sobre o enraizamento.

Segundo Assis et al. (2004), a intensidade de luz pode influenciar fortemente a produção e enraizamento de estacas pela redução ou aumento de substâncias fenólicas endógenas, as quais podem agir como inibidores ou promotores, dependendo das concentrações nos tecidos e da espécie. Segundo esses mesmo autores, a luz também pode afetar a concentração endógena de citocininas, que possuem funções inibidoras do enraizamento. Para Gontijo et al. (2003), tão importante quanto a concentração dos reguladores de crescimento na indução da rizogênese adventícia é a existência de um adequado balanço hormonal endógeno, especialmente entre auxinas, giberelinas e citocininas, culminando em um equilíbrio adequado de promotores e inibidores do processo de iniciação radicular, o que pode não ter ocorrido devido às condições locais de clima semiárido, uma vez que a temperatura tem importante função regulatória no metabolismo das plantas, afetando de forma positiva ou negativa o enraizamento (CUNHA et al., 2009), ao elevar a taxa de transpiração e favorecer a brotação das gemas antes que o enraizamento tenha ocorrido (FACHINELLO et al., 2005)

A formação de calo e de raízes são processos independentes. Nos dois experimentos ocorreu formação de calos nas estacas sem a formação de raízes. Indicando que o cacaueiro deve-se encontrar no grupo das espécies em que um ou mais co-fatores de enraizamento são limitantes, podendo a auxina ser ou não limitante devido à falta de determinados co-fatores, o que necessitaria, portanto, combinar o uso de auxinas com a presença de folhas ou de outra técnica de condicionamento, a fim de se obter sucesso no enraizamento (HARTMANN et al., 1990).

Quadro 1 - Resumo do quadro de análise de variância (Q.M.) para percentagens de sobrevivência (Sob.), de brotações (Brot.) e de formação de calos (Cal.) em estacas no experimento I e sobrevivência (Sob.) e formação de calos (Cal.) no experimento II.

\begin{tabular}{lcccclcccc}
\hline & \multicolumn{4}{c}{ Experimento I } & \multicolumn{3}{c}{ Experimento II } \\
\hline Fatores & G.L. & Q.M. & Q.M. & Q.M. & Fatores & G.L. & Q.M. & Q.M. \\
\hline AIB & 3 & $1,583 \mathrm{~ns}$ & $0,531 \mathrm{~ns}$ & $1,458 \mathrm{~ns}$ & Blocos & 3 & $0,166 \mathrm{~ns}$ & $0,229 \mathrm{~ns}$ \\
Clones & 1 & $0,500 \mathrm{~ns}$ & $1,531 \mathrm{~ns}$ & $3,125 *$ & AIB & 3 & $0,166 \mathrm{~ns}$ & $0,229 \mathrm{~ns}$ \\
AIB x & \multirow{2}{*}{3} & $0,083 \mathrm{~ns}$ & $0,281 \mathrm{~ns}$ & $0,125 \mathrm{~ns}$ & Resíduo & 9 & $0,333 \mathrm{~ns}$ & $0,118 \mathrm{~ns}$ \\
Clones & & & & & & & & & \\
\end{tabular}


(PEREIRA et al., 2015)

ns = não significativo $(\alpha \leq 0,05)$

Quadro 2 - Percentagem de sobrevivência de estacas dos clones de cacaueiro CCN-51 e PS-1319.

\begin{tabular}{cc}
\hline Clones & Sobrevivência $(\%)$ \\
\hline CCN-51 & $1,125 \mathrm{a}$ \\
PS-1319 & $0,875 \mathrm{a}$ \\
\hline
\end{tabular}

Quadro 3 - Percentagens de brotação e de formação de calos em estacas dos clones de cacaueiro CCN-51 e PS-1319.

\begin{tabular}{ccc}
\hline Clones & Brotação $(\%)$ & Calos $(\%)$ \\
\hline CCN-51 & $0,813 \mathrm{a}$ & $1,250 \mathrm{a}$ \\
PS-1319 & $0,375 \mathrm{a}$ & $0,625 \mathrm{~b}$ \\
\hline
\end{tabular}

Quadro 4 - Percentagens de sobrevivência e de formação de calos em estacas do clone de cacaueiro PH-16, em função das concentrações de AIB.

\begin{tabular}{ccc}
\hline AIB $\left(\mathrm{mg} . \mathrm{L}^{-1}\right)$ & Sobrevivência $(\%)$ & Calos $(\%)$ \\
\hline 0 & $1,50 \mathrm{a}$ & $2,00 \mathrm{a}$ \\
300 & $1,75 \mathrm{a}$ & $2,00 \mathrm{a}$ \\
600 & $1,50 \mathrm{a}$ & $1,75 \mathrm{a}$ \\
900 & $1,25 \mathrm{a}$ & $1,50 \mathrm{a}$ \\
\hline
\end{tabular}

\section{Conclusão}

A propagação de cacaueiros através de estacas semilenhosas é inviável, mesmo que submetidas a aplicações exógenas de AIB e mantidas em ambiente com umidade relativa do ar controlada.

\section{Referências}

ASSIS, T. F.; FETT-NETO, A. G.; ALFENAS, A. C. Current techniques and prospects for the clonal propagation of hardwood with emphasis on Eucalyptus. In: WALTER. C.; CARSON, M. Plantation forest biotechnology for the $21^{\text {th }}$ century. New Delhi: Research Sign Post, v. 1 p. $303-333,2004$.

BASTOS, D. C.; SCARPARE FILHO, J. A.; FATINANSI, J. C.; PIO, R. Estiolamento, incisão na base da estaca e uso de AIB no enraizamento de estacas herbáceas de caramboleira. Revista Brasileira de
Fruticultura, Jaboticabal, v. 27, n. 2, p. 281284, 2005.

BASTOS, D. C.; PIO, R.; SCARPARE FILHO, J. A.; LIBARDI, M. N.; ALMEIDA, L. F. P.; ENTELMANN, F. A.Enraizamento de estacas lenhosas e herbáceas de cultivares de caquizeiro com diferentes concentrações de ácido indolbutírico. Revista Brasileira de Fruticultura, Jaboticabal, v. 27, n. 1, p. 182184, 2005.

CUNHA, A. C. M. C. M.; PAIVA, H. N.; LEITE, H. G.; BARROS, N. F.; LEITE, F. P. Relações entre variáveis climáticas com produção e enraizamento de miniestacas de eucalipto. Revista Árvore, Viçosa, v. 33, n. 2, p. 195-203, 2009.

FACHINELLO, J. C.; HOFFMANN, A.; NACHTIGAL, J. C. Propagação de plantas frutíferas. Brasília: Embrapa Informação Tecnológica, 2005. 221 p. 
FARIA, J. C.; SACRAMENTO, C. K. Enraizamento e crescimento de estacas herbáceas do cacaueiro (clones Cepec 42, TSH 516 e TSH 1188) em função da aplicação do ácido indolbutírico (AIB). Revista Brasileira de Fruticultura, Jaboticabal, v. 25, n. 1, p. 192-194, 2003.

GONTIJO, T. C. A.; RAMOS, J. D.; MENDONÇA, V.; PIO, R.; ARAÚJO NETO S. E.; CORRÊA, F. L. O. Enraizamento de diferentes tipos de estacas de aceroleira utilizando ácido indolbutírico. Revista Brasileira de Fruticultura, Jaboticabal, v. 25, n. 2, p. 290-292, 2003.

HARTMANN, H. T.; KESTER, D. E.; DAVIES JUNIOR, F. T. Plant propagation: principles and practices. 5. ed. Nova Jersey: Ed. Prentice Hall, 1990. 647 p.

LEITE, J.B.V.; MARTINS, A. B. G. Efeito do ácido indolbutírico e época de coleta no enraizamento de estacas semi-lenhosas do cacaueiro. Revista Brasileira de Fruticultura, Jaboticabal, v. 29, n. 2, p. 204-208, 2007.

LIMA, R. L. S.; SIQUEIRA, D. L.; WEBER, O. B.; CAZETTA, J. O. Comprimento de estacas e parte do ramo na formação de mudas de aceroleira. Revista Brasileira de Fruticultura, Jaboticabal, v. 28, n. 1, p. 83-86, 2006.

LOPES, J. C.; ALEXANDRE, R. S.; SILVA, A. E. C.; RIVA, E.M. Influência do ácido indol-3butírico e do substrato no enraizamento de estacas de acerola. Revista Brasileira de Agrociência, Pelotas, v. 9, n. 1, p. 79-83, 2003.

MACHADO, M. P.; MAYER, J. L. S.; RITTER, M.; BIASI, L. A. Ácido indolbutírico no enraizamento de estacas semilenhosas do porta-enxerto de videira 'VR 043-43' (Vitis vinifera $\mathrm{x}$ Vitis rotundifolia). Revista Brasileira de Fruticultura, Jaboticabal, v. 27, n. 3, p. 476-479, 2005.
NORBERTO, P. M.; CHALFUN, N. N. J.; PASQUAL, M.; VEIGA, R. D.; PEREIRA, G. E.; MOTA, J. H. Efeito da época de estaquia e do AIB no enraizamento de estacas de figueira (Ficus carica L.). Revista Ciência e Agrotecnologia, Lavras, v. 25, n. 3, p. 533541, 2001.

PASQUAL, M.; CHALFUN, N. N. J.; RAMOS, J. D.; VALE, M. R. do; SILVA, C. R. de R. Fruticultura comercial: propagação de plantas frutíferas. Lavras: UFLA/FAEPE, 2001. $137 \mathrm{p}$.

PEREIRA, M. C.; SANTOS, L. S.; RIBEIRO V. G.; SOUZA, E. R.; ARAUJO, E. A.; PEIXOTO, A. R. Avaliações de porta-enxertos de cacaueiros da fase de crescimento das mudas até a enxertia no campo, no semiárido baiano. Revista Agrotrópica, Itabuna, v. 21, n. 2, p. 510, 2009.

PYKE, E. E. The vegetative propagation of cacao. II. Softwood cuttings. Annual Report on Cacao Research, v. 2, n. 1, p. 3-9, 1933.

SANTOS JUNIOR, A. J.; ALMEIDA, A-A. F.; SILVA, D. C.; FARIA, J. C.; MIELKE, M. S.; GOMES, F. P. Enraizamento de estacas, crescimento e respostas anatômicas de mudas clonais de cacaueiro ao ácido indol-3-butírico. Revista Brasileira de Fruticultura, Jaboticabal, v. 30, n. 4, p. 1071-1082, 2008.

SODRÉ, G. A.; CORA, J. E. Substratos para enraizamento de miniestacas de cacaueiro. Revista Agrotrópica, Itabuna, v. 19, n. 1, p. 39-42, 2007.

VALE, M. R.; CHALFUN, N. N.; MENDONÇA, V.; MIRANDA, C. S.; COELHO, G. V. A.. Ácido indolbutírico e sacarose no enraizamento de estacas de goiabeira cultivar Paluma. Revista Caatinga, Mossoró, v. 21, n. 3, p. 69-74, 2008.

VILLA, F.; PIO, R.; CHALFUN, N. N. J.; GONTIJO, T. C. A.; DUTRA, L. F. Propagação de amoreira-preta utilizando estacas lenhosas. 
(PEREIRA et al., 2015)

Revista Ciência e Agrotecnologia, Lavras, v.

27, n. 4, p. 829-834, 2003. 